\title{
Forecasting Crude Oil Spot Price U sing OECD Petroleum Inventory Levels
}

\author{
MICHAEL YE, ${ }^{*}$ JOHN ZYREN, ${ }^{* *}$ AND JOANNE SHORE**
}

\begin{abstract}
A bstract
This paper presents a short-term monthly forecasting model of W est Texas Intermediate crude oil spot price using OECD petroleum inventory levels. Theoretically, petroleum inventory levels are a measure of the balance, or imbalance, between petroleum production and demand, and thus provide a good market barometer of crude oil price change. B ased on an understanding of petroleum market fundamentals and observed market behavior during the post-Gulf $W$ ar period, the model was developed with the objectives of being both simple and practical, with required data readily available. As a result, the model is useful to industry and government decision-makers in forecasting price and investigating the impacts of changes on price, should inventories, production, imports, or demand change. (J EL Q 40, C53); Int'I Advances in Econ. Res., 8 (4): pp. 324-33, Nov 02. ()All Rights Reserved
\end{abstract}

\section{Introduction}

Both government and the industrial sector have an interest in forecasting crude oil spot price. Potential changes in world petroleum supply-demand fundamentals, such as quota changes of the Organization of the Petroleum Exporting Countries (OPEC), result in questions on the implications for the crude oil price. Because petroleum inventory levels are a measure of the balance, or imbalance, between petroleum production and demand, they reflect changing market pressures on crude oil prices, and thus provide a good market barometer of crude oil price change in the short run. This paper presents the development of a short-term monthly forecasting model for West Texas Intermediate crude oil spot price using Organization for Economic Cooperation and Development (OECD) petroleum inventory levels. This model was built based on an understanding of petroleum market fundamentals and the observed market behavior during the post-Gulf War period from January 1992 to February 2001. The results from the forecasting model empirically demonstrate that petroleum inventories are a good market indicator of crude oil price change.

The relationship between commodity inventory levels and price has been studied for nearly a century, tracing back to the early published works of Working [1934] and Kaldor [1939], where the classical theory of storage was developed to explain why price backwardation occurred. Empirical studies were also carried out on agricultural commodity markets, see for example, Working [1934], Brennan [1958], and Telser [1958]. In recent publications, Pindyck [1994] empirically studied the relationship between inventories and short-run commodity prices using copper, lumber, and heating oil data. Dale and Zyren [1997] particularly

\footnotetext{
${ }^{*}$ St. Mary's College of Maryland and ${ }^{* *}$ Department of Energy-U.S.A. This work is partially sponsored by the Office of Strategic Petroleum Reserve, Department of Energy, USA, and was presented at the International Atlantic Economic Conference, Athens, Greece, March 2001.
} 
pointed out that energy futures markets behave similarly to futures markets for agricultural commodities. $^{1}$

The literature on crude oil and petroleum product markets is enormous. For example, the book by Horsnell and Mabro [1993] addressed the Brent market and the formation of world oil prices. $^{2}$ A recent paper by Pindyck [2001] is most closely related to the analysis. He described the short-run dynamic relationship between commodity prices and inventories, using the petroleum markets for illustrations. Specifically, he explained the equilibrium in two interconnected markets: a cash spot market and a market for storage. Also related is a paper by Considine and Larson [2001], who studied the presence of risk premiums on crude oil inventories.

It was found that the existing models dealing with commodity price and inventory in the general equilibrium framework, or addressing specific theoretical and econometric issues, provide insight into fundamental understanding of the economics behind the market behavior. However, they require too much expertise and specific data to be implemented in a policy environment by professionals without substantial economic and statistical training. As a result, a simple and a practical short-term crude-oil-price forecasting model was developed that is intuitively appealing to decision-makers and can therefore be easily interpreted and accepted. The model is also practical from a maintenance standpoint in that it is based on a single, readily available data series-petroleum inventories.

The next section provides background on the petroleum market, reviewing West Texas Intermediate (WTI) crude oil spot prices and OECD total petroleum inventories for the last decade. The following section gives the empirical study a theoretical foundation, explaining why petroleum prices and inventories are related. Next is an analysis of the data collected for the study, followed by a presentation of the forecast model and results. The final section concludes the paper and suggests avenues for future investigation.

\section{Crude Oil M arket in the R ecent Decade}

The petroleum market in the 1990s exhibited several features that allowed for the establishment of quantitative insights between crude oil prices and market fundamentals. Over much of the time between 1990 and the present, OPEC did relatively little to adjust production to accommodate demand changes, and sometimes, when action was taken, it was either insufficient or excessive. Thus, there has been a fairly long period in which prices exhibited some rather large cyclical swings, as shown in Figure 1.

Figure 2 shows how OECD crude oil supply and demand for petroleum varied over the last decade. Global demand for petroleum products is highly seasonal and is greatest during the winter months, when countries in the Northern Hemisphere increase their use of distillate heating oils and residual fuels. Supply of crude oil, including both production and net imports, also shows a similar seasonal variation but with smaller magnitude. During the summer months, supply exceeds demand and OECD petroleum inventories normally build; whereas during the winter, demand exceeds supply and inventories are drawn down. As a result, inventories also demonstrate seasonality. If market supply and demand are balanced over the period of a year, the increase in inventories over the summer will equal the decline in inventories during the winter.

As indicated in Figure 2, the market was well out of balance in 1998 due to slowing demand growth and increasing supply. Two warm winters and the Asian financial crisis diminished demand growth both seasonally during the winter months and over the entire year, while supply increased substantially as Iraqi crude oil came back into the export market in 1997 through the Oil-for-Food Program. During this time, supply outstripped demand and 


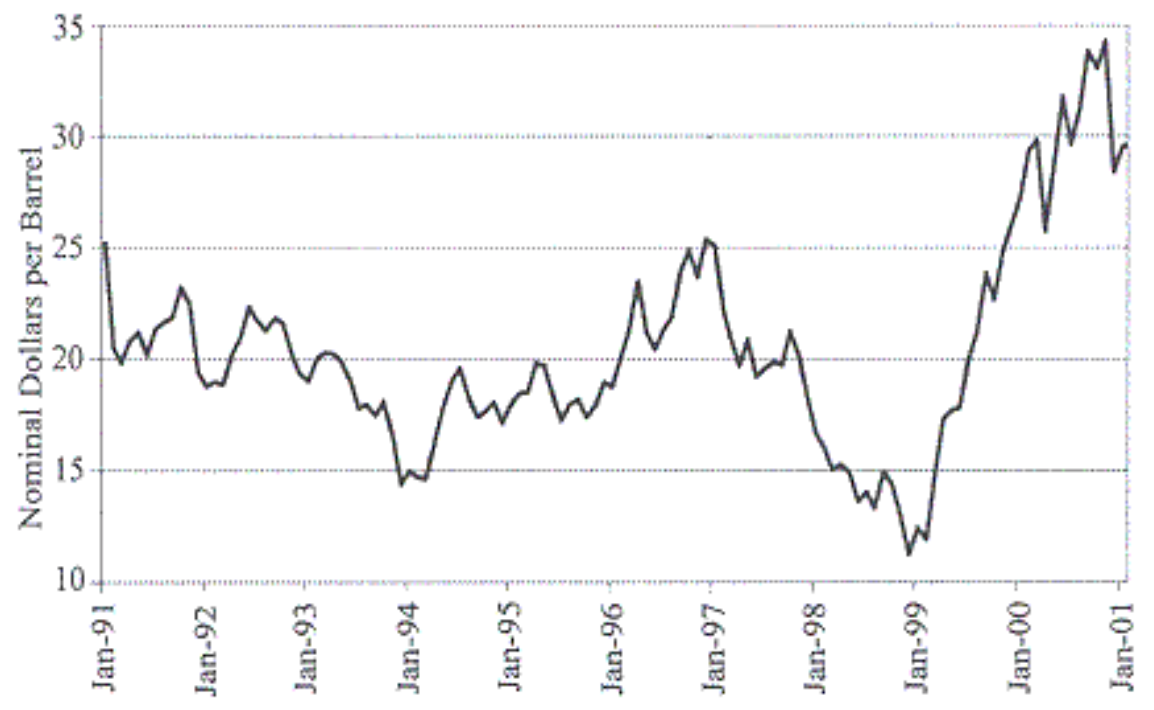

Figure 1: Monthly Average WTI Crude Oil Spot Price

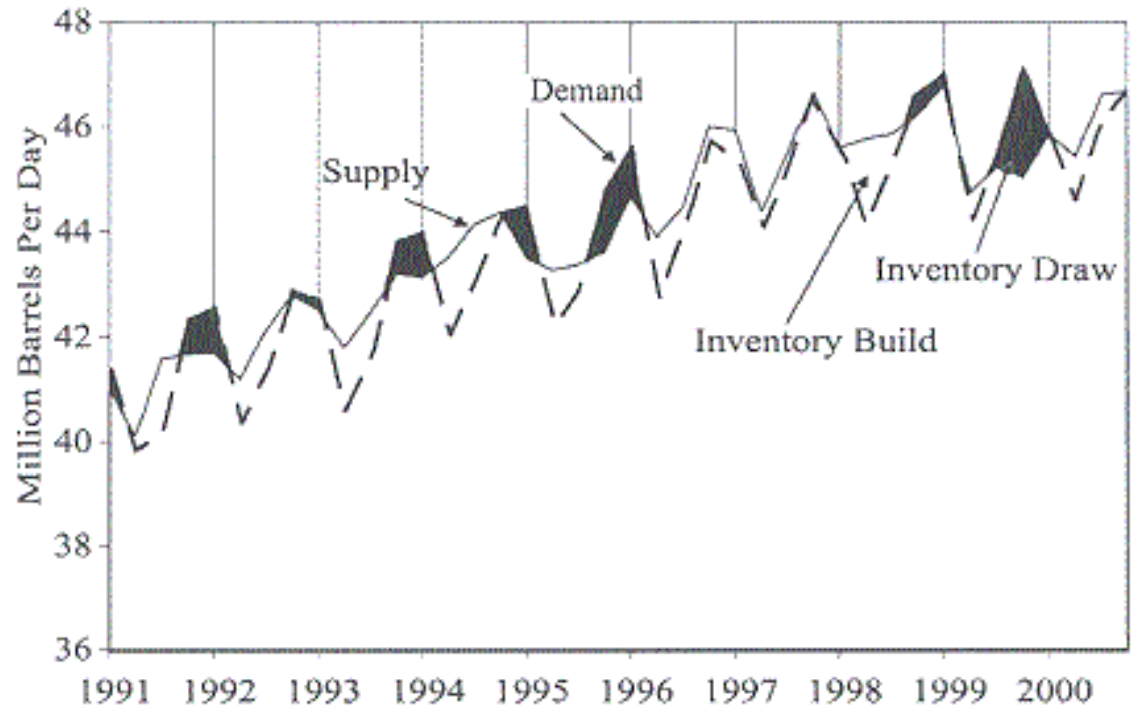

Figure 2: OECD Crude Oil Supply and Petroleum Demand 


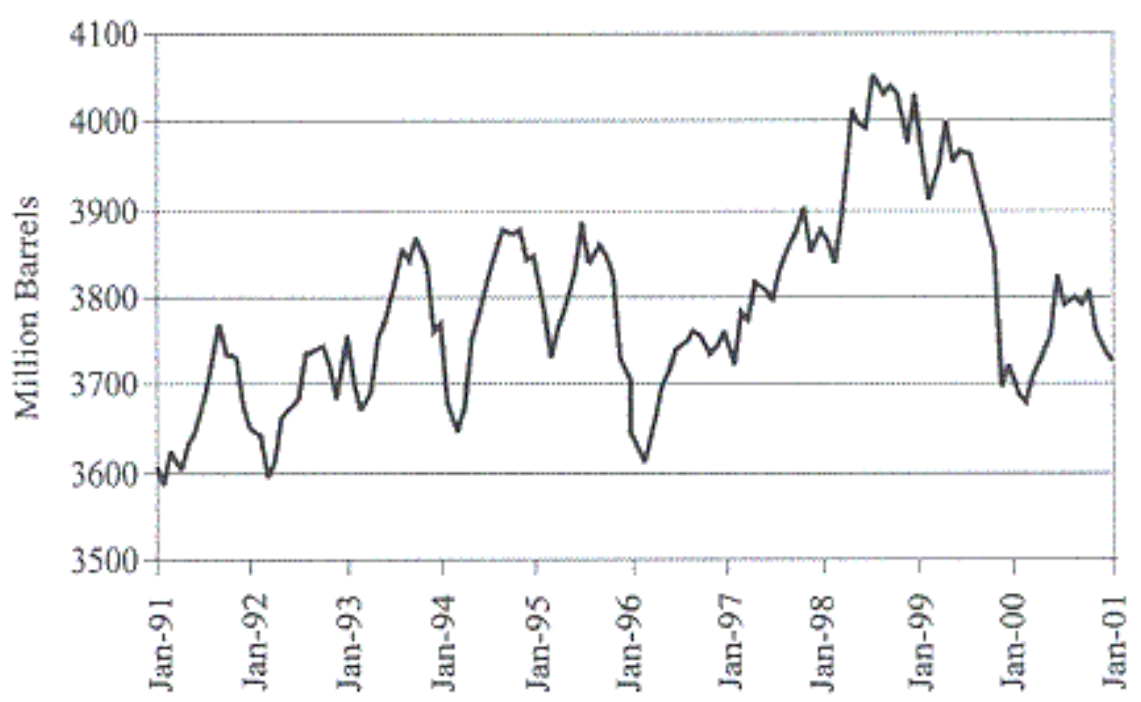

Figure 3: Total OECD Petroleum Inventory

inventories grew to unusually high levels (see Figure 3). Referring back to Figure 1, it is observed that WTI crude oil spot prices fell to near $\$ 10$ per barrel by the end of 1998 , due to the excess of production over demand and the resulting inventory build. In March 1999, OPEC agreed to cut back production to a level well below demand, and also during this time, the Asian economies had an unexpectedly quick recovery, which increased the demand for crude oil. Thus, during 1999, the supply-demand imbalance reversed, and with demand exceeding production, inventories were used to help meet demand. The excess inventories that had been built up fell rapidly to below normal, and WTI crude spot prices rose to over $\$ 30$ per barrel by early March 2000 .

Figure 3 shows how total OECD petroleum inventories, defined as the sum of government stocks and commercial stocks of both crude oil and petroleum products, have changed over time. In particular, note the large excess and then underage of inventories over the past several years relative to variations away from some kind of normal level seen in the first half of the decade. Such an observed normal level in OECD inventories is theoretically as well as empirically important when exploring inventory relationships to price. If the peak inventory level reached during the summer months is lower than normal, it indicates less-than-normal inventory will be available to supply the upcoming high-demand winter months, and prices would be expected to increase.

The relative inventory level will be defined as the deviation of actual inventories from a well-defined normal, or desired, level in the next section. Then, the desired normal levels will be empirically determined and the relative inventories will be derived in the fourth section. Inventories are seasonal as seen from Figure 3, often building in the summer months and dropping during the winter. As has been argued previously, inventories demonstrate seasonality because their build-ups and draw-downs reflect the seasonal imbalance between supply and demand as a result of the supply of crude oil showing less seasonal variation than demand. Long-term trends also exist, mainly due to the trends in government inventories. 
Such trends will also be considered when defining a desired normal pattern.

\section{Crude Oil M arket Fundamentals}

It has been observed that petroleum inventories have the following characteristics. First, inventories of crude oil are readily available to refineries (petroleum product manufacturers) for production of products such as gasoline and distillate heating oil, and inventories of primary petroleum products are readily available to be sold to end users. Second, prices seem to be more responsive in the short-term to inventories than to production because inventories are the marginal source of supply. Third, inventories are needed to cushion a system that delivers products in batches. Fourth, companies build or draw down discretionary inventories based on their price expectations and sale opportunities. Finally, inventories also build or fall due to uncertainties or unexpected changes in production and demand. ${ }^{3}$

Regardless of the cause of their change, inventories provide a measure of whether production is in excess of demand, how much in excess, and for how long. As such, inventory behavior can be an indicator of market pressure on price changes. In the case of petroleum, when crude oil production and refinery production exceed demand for crude oil and petroleum products, commercial inventories of crude oil and products will build and vice versa. Specifically, for the world market, assuming no losses or volume changes during processing, the following balance equation can be written:

$$
\text { Demand }_{\mathrm{t}}=\text { Production }_{\mathrm{t}}-\text { Inventory Change }_{\mathrm{t}} \quad .
$$

Since InventoryChange $\mathrm{t}_{\mathrm{t}}=$ Inventor $_{\mathrm{t}}-$ Inventor $_{\mathrm{t}-1}$, , (1) implies:

$$
\text { Inventory }_{\mathrm{t}}=\text { Inventory }_{\mathrm{t}-1}-\left(\text { Demand }_{\mathrm{t}}-\text { Production }_{\mathrm{t}}\right) \quad \text {. }
$$

As shown in Figure 4, and assuming initial equilibrium inventories, if demand exceeds production in a given month, inventories will be drawn down below desired normal levels and there will be positive price pressure. The direction and speed with which inventories are changing indicate the direction and magnitude of the demand and supply imbalance. For example, during spring and summer months, it is typical industry practice to replenish product inventories by refining more products than are demanded. This inventory increase is normal and expected, and would result in no price pressure. It is only in situations where the inventories are not being built to desired normal levels that positive price pressure would exist.

It is important to note that the equilibrium price in a given month is at the point where the difference between supply and demand is normal, taking into account any possible seasonality and trend. In other words, the equilibrium price is achieved when the relative inventory level, defined as the deviation of actual inventory level from its corresponding desired normal level, is zero. The concept of relative inventory level is crucial. It indicates if the market is tight or loose, and thus indicates increases or decreases in price pressure. The goal of this paper is to build a forecast model based on the relationship between the crude oil price and the relative inventories of petroleum.

\section{A nalysis}

The analyses began with the assumption that there is a relationship between price and supply-demand fundamentals. The relative inventory variable is an explicit measure of the balance between production and demand. Thus, relative inventory is a good variable to indicate the state of the supply-demand balance as it impacts price. 


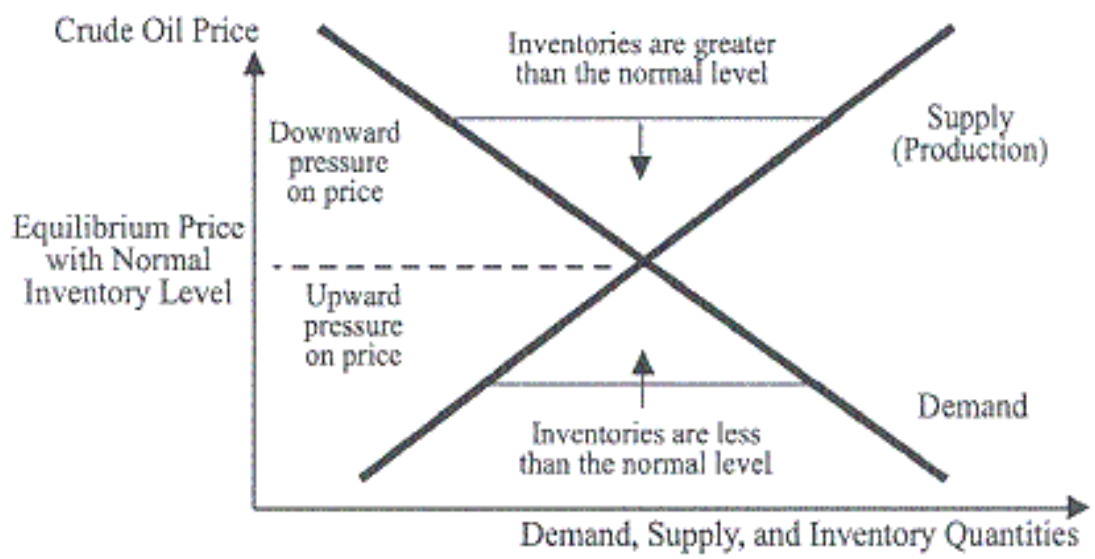

Figure 4: An Illustration of Supply, Demand, and Inventory Behavior on Price

The relative inventory level, denoted by $R I N_{\mathrm{t}}$, is defined as:

$$
R I N_{\mathrm{t}}=I N_{\mathrm{t}}-I N_{\mathrm{t}}^{*}
$$

where $I N_{\mathrm{t}}$ is the actual total OECD petroleum inventory level, government and commercial, in month $t$, and $I N_{\mathrm{t}}^{*}$ is the normal, or desired, level. More specifically, let $D_{\mathrm{k}}, k=2,3, \ldots, 12$ be the 11 monthly seasonal variables. The desired inventory level is calculated by:

$$
I N_{\mathrm{t}}^{*}=a_{0}+b_{1} t+\sum_{\mathrm{k}=2}^{12} b_{\mathrm{k}} D_{\mathrm{k}},
$$

in which $a_{0}, b_{1}$, and $b_{\mathrm{k}}, k=2, \ldots, 12$ are estimated coefficients from de-trending and deseasonalizing the observed total OECD petroleum inventory. Regression results show a statistically significant seasonal pattern in inventory as well as a consistent positive growth for this period.

Figure 5 shows the desired normal level of total OECD inventories as compared to the observed level. This empirically determined normal level demonstrates a positive trend and the expected seasonal movements. The difference between the observed inventory level and the corresponding desired normal level is the so-called relative inventory level or the deseasonalized and de-trended inventory level, reading from the right vertical axis in the figure.

For crude oil prices, the nominal West Texas Intermediate crude oil spot price is used, which is considered a world marker crude oil spot price. Another price often viewed as a marker crude oil spot price is Brent. However, it was found that the two price series are highly correlated and move in very much the same pattern, with monthly WTI crude oil spot price higher than Brent throughout the period, except for temporary daily or weekly price inversions. These daily spot prices were obtained from Platts Data Service.

For inventories, data of government and commercial inventories of crude oil and petroleum products for all OECD countries are available from March 1984 to the present for all OECD countries, but the International Energy Agency (IEA) changed its data collection methodology in December 1990. It was decided to limit the current study to the period from January 1992 to February 2001 to avoid the Gulf War impacts on the market and to limit the analysis 


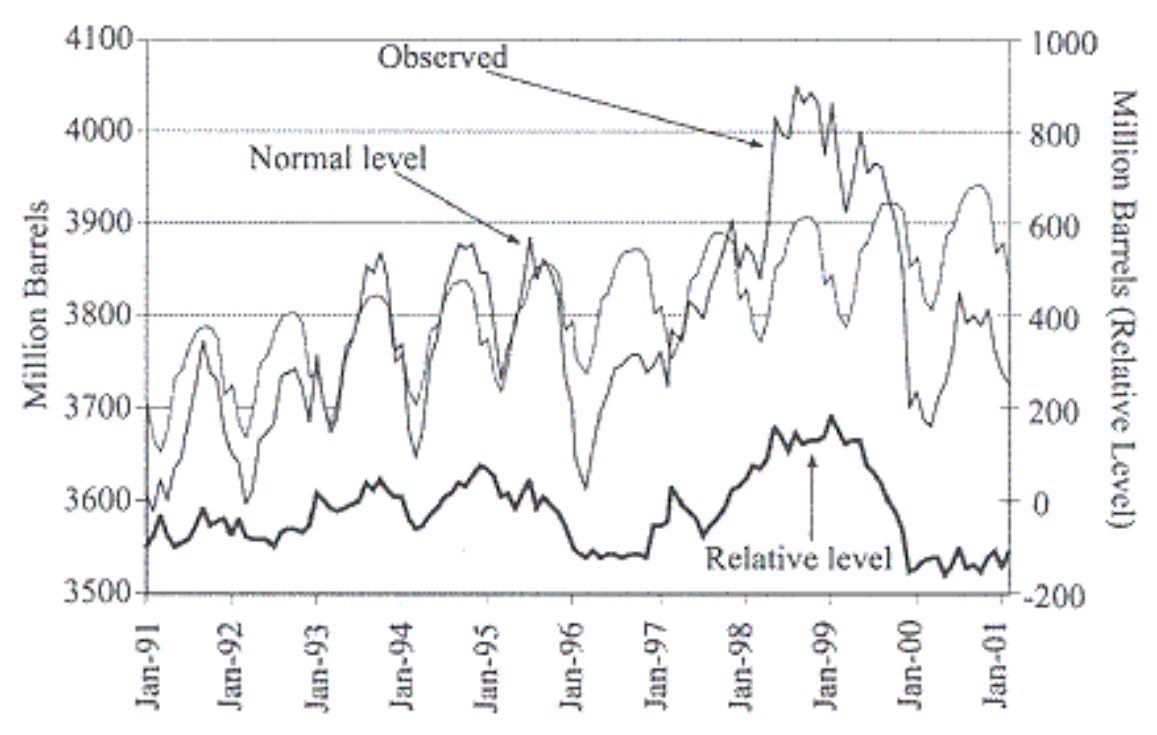

Figure 5: The Normal Level of OECD Petroleum Inventory

to a consistent data series. Since OECD inventory data are only available monthly, the daily crude oil spot prices were aggregated to a monthly frequency.

The correlation coefficient that was found between West Texas Intermediate crude oil spot price and total OECD inventory is -0.422 , which is significant at the 99 percent confidence level, clearly demonstrating the expected negative price-inventory relationship. Furthermore, it was found that WTI crude oil spot price has a single unit root, and the de-trended and deseasonalized total OECD inventory variable also has a single unit root; however, a Johansen co-integration test with intercept, no trend, and four lags finds no evidence of a co-integrating relationship between these two variables. Additionally, the Error Correction Models (ECMs) investigated for this study do not find the ECM variable to be statistically significant.

\section{A Forecast Model}

The study sought to build a dynamic forecast equation that can be applied in a simple, spreadsheet environment using explanatory variables that can easily be forecasted into the future. In the process of determining the appropriate supply-demand variables, it was found that in most cases, OECD variables provided better price forecasts than the variables from the United States alone, since OECD represents a larger proportion of the world demand as well as inventory. Variables like crude oil production, product production, and product demand became statistically insignificant as explanatory variables in the presence of an inventory variable. Moreover, combined government and commercial inventories gave better price forecasts than commercial inventory alone; and the sum of crude oil inventory and petroleum product inventories performed better than crude oil inventory alone. ${ }^{4}$

It was found that current and lagged values of deviations from the desired normal level of total OECD inventories led to the best forecasts of nominal crude oil price. ${ }^{5}$ Specifically, the forecast model developed is: 


$$
W T I_{\mathrm{t}}=a+\sum_{\mathrm{i}=0}^{5} b_{\mathrm{i}} R I N_{\mathrm{t}-\mathrm{i}}+\sum_{\mathrm{i}=0}^{5} c_{\mathrm{i}} L I N_{\mathrm{t}-\mathrm{i}}+d A I N_{\mathrm{t}}+e W T I_{\mathrm{t}-1}+\varepsilon_{\mathrm{t}}
$$

in which $W T I$ is the nominal West Texas Intermediate crude oil spot price; subscript $t$ is for the $t$ th month; subscript $i$ is for the $i$ th month prior to the th month; $a, b_{\mathrm{i}}, c_{\mathrm{i}}, d$, and $e$, for $i=0,1,2, \ldots, 5$, are coefficients to be estimated; $R I N$, as defined in (3), is the relative total OECD inventory level, that is, the deviations of actual stock levels, $I N$, from their corresponding desired normal levels, $I N^{*} ; L I N$ is a low inventory variable, defined to capture the asymmetric market behavior characterized by a different price response to inventory changes when the inventory level is below the desired normal level than when the inventory level is above normal, that is:

$$
L I N_{\mathrm{t}}=R I N, \text { if } I N_{\mathrm{t}}<I N_{\mathrm{t}}^{*}, \text { and } L I N_{\mathrm{t}}=0, \text { otherwise; }
$$

$A I N$ is defined as the annual differences in monthly inventory to reflect cyclical market behavior not captured by the monthly seasonal variables in the de-trending and de-seasonalizing estimation ${ }^{6}$, that is:

$$
A I N_{\mathrm{t}}=I N_{\mathrm{t}}-I N_{\mathrm{t}-12}
$$

and $\varepsilon$ is the random term.

Notice that the model expressed in (5) can be viewed in the framework of a partial adjustment model, since $R I N$ is the relative inventory (the deviation of $I N$ from its corresponding desired normal level, $\left.I N^{*}\right)$.

In order to reduce multicollinearity, (5) was isomorphically transformed and estimated as:

$W T I_{\mathrm{t}}=a+\sum_{\mathrm{i}=0}^{4} b_{\mathrm{i}} \Delta R I N_{\mathrm{t}-\mathrm{i}}+b_{5} R I N_{\mathrm{t}-5}+\sum_{\mathrm{i}=0}^{4} c_{\mathrm{i}} \Delta L I N_{\mathrm{t}-\mathrm{i}}+c_{5} L I N_{\mathrm{t}-5}+d A I N_{\mathrm{t}}+e W T I_{\mathrm{t}-1}+\varepsilon_{\mathrm{t}}$.

Table 1 shows the results obtained from an OLS regression. The adjusted $R^{2}$ is 0.935 , the standard error of regression is $\$ 1.24$ per barrel, the Akaike information criterion equals 3.3945, the Durbin-Watson statistic is 2.05, and the Root Mean Squared Error (RMSE) for the dynamic in-sample forecast over the entire estimation period is at a low value of $\$ 1.63$ per barrel. ${ }^{7}$ 


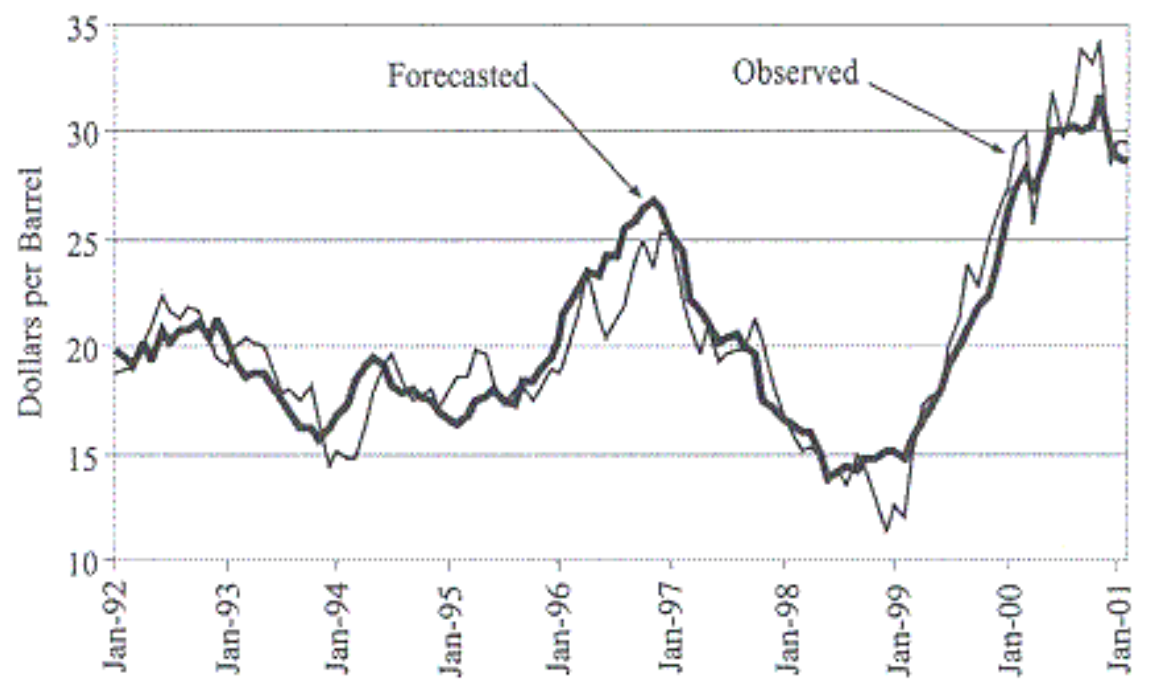

Figure 6: A Dynamic Forecast of WTI Using OECD Petroleum Inventory

TABLE 1

OLS Regression Results

\begin{tabular}{lrcrc}
\hline \hline Variable & Coefficient & Standard Error & $t$-Statistic & $p$-Value \\
\hline$C$ & 3.446132 & 1.039523 & 3.315109 & 0.0013 \\
$W T I_{\mathrm{t}-1}$ & 0.808695 & 0.055134 & 14.667920 & 0.0000 \\
$A I N_{\mathrm{t}}$ & -0.004402 & 0.002036 & -2.161928 & 0.0331 \\
$\Delta R I N_{\mathrm{t}}$ & 0.001185 & 0.007656 & 0.154817 & 0.8778 \\
$\Delta R I N_{\mathrm{t}-1}$ & -0.017438 & 0.007709 & -2.262014 & 0.0260 \\
$\Delta R I N_{\mathrm{t}-2}$ & -0.008669 & 0.008288 & -1.045917 & 0.2983 \\
$\Delta R I N_{\mathrm{t}-3}$ & -0.023460 & 0.008215 & -2.855632 & 0.0053 \\
$\Delta R I N_{\mathrm{t}-4}$ & 0.006147 & 0.008787 & 0.699563 & 0.4859 \\
$R I N_{\mathrm{t}-5}$ & -0.015873 & 0.006544 & -2.425502 & 0.0172 \\
$\Delta L I N_{\mathrm{t}}$ & -0.003635 & 0.009459 & -0.384269 & 0.7016 \\
$\Delta L I N_{\mathrm{t}-1}$ & 0.002913 & 0.009703 & 0.300245 & 0.7646 \\
$\Delta L I N_{\mathrm{t}-2}$ & 0.005978 & 0.009829 & 0.608170 & 0.5445 \\
$\Delta L I N_{\mathrm{t}-3}$ & 0.021788 & 0.009939 & 2.192060 & 0.0308 \\
$\Delta L I N_{\mathrm{t}-4}$ & -0.005157 & 0.010272 & -0.502036 & 0.6168 \\
$L I N_{\mathrm{t}-5}$ & 0.017443 & 0.007243 & 2.408322 & 0.0180 \\
\hline
\end{tabular}

Figure 6 shows an in-sample dynamic forecast of WTI crude oil price using (7) and the actual WTI crude oil spot price in December 1991 as the starting value.

This model is designed to dynamically forecast crude oil spot price, using reported and predicted inventories. An important feature of any forecasting model is that a forecast of the independent variables be available. On a routine basis, the U.S. Energy Information Administration (EIA) forecasts monthly OECD inventory levels in conjunction with its ShortTerm Energy Outlook (STEO). Furthermore, other organization's forecasts of OECD supply and demand, such as those projected by the IEA, can be used to derive forecasted inventory 
levels.

Another desired feature of our model is that it be simple enough to implement easily in a spreadsheet or other software package, and that the variables be easy to change and update. The simplicity and ease of updating makes this model attractive for investigating various scenarios to see the impacts of market changes on crude oil spot price, should inventories, production, imports, or demand change for any reason. Moreover, the forecast equation reflects the market behavior differences between cases when inventory levels are below the normal levels relative to cases when inventory levels are above the desired normal levels. Finally, the model itself can be easily updated periodically should there be a fundamental structure change or a shift in the normal level of inventories.

\section{Conclusions and Suggestions for Future Work}

This paper presented a simple and practical dynamic forecast model. It also demonstrated the relationship between petroleum inventories and crude oil prices from January 1992, the period immediately following the Gulf War, to February 2001. EIA uses this model to investigate future price impacts of OPEC production changes and to estimate price effects of market disruptions by using monthly inventories derived from a two year forecast of OECD supply-demand balances published in EIA's STEO.

A number of areas merit further exploration for potential model improvement. First, it would be interesting to see how inventory levels may relate to crude oil market volatility. For example, does higher price volatility occur when relative inventories are low versus normal? In order to investigate this issue, a proper measure of market volatility is needed. ${ }^{8}$

A second possible extension would be the investigation of abnormal market behavior such as the Gulf War or periods of low or high inventories. It is not clear if market variable relationships are the same during normal situations as during very tight or very loose markets.

\section{Footnotes}

\footnotetext{
${ }^{1}$ Numerous studies were carried out on this subject in both developing various theories and empirically testing these theories on an array of commodities, for example, grains [Gustafson, 1958], finished goods [Maccini and Rossana, 1984], and refined copper [Thurman, 1988]. Other related studies can be found in Eichenbaum [1989], Ramey [1989], Williams and Wright [1991], Blinder and Maccini [1991], Deaton and Laroque [1992; 1996], Miranda and Glauber [1993], Chambers and Bailey [1996], and Brennan, and Williams, and Wright [1997].

${ }^{2}$ Other sources are also informative, see for example, Mabro [1992], and Razavi and Fesharaki [1991].

${ }^{3}$ Another related characteristic is the joint production of petroleum products. For an in-depth treatment on the subject, see Pindyck [1994] and Considine [1997].

${ }^{4}$ Detailed records on these investigations are available upon request.

${ }^{5}$ Number of lags is determined according to AIC. The authors benefited from a conversation with W. Enders in determining the number of lags of the dependent variables and the relevant chapter in his book (Enders [1995]).

${ }^{6}$ As seen from Figure 1, there have been two big cycles in crude oil price during the 1990s. Due to this limited number of observed big cycles, the explanatory variable $\mathrm{AII}$ is used in the forecast equation to try to capture this feature.

${ }^{7}$ In order to maintain a simple form, insignificant variables were retained, even though they provide a negligible improvement in dynamic forecast ability.

${ }^{8} \mathrm{Hull}$ [2000] provides a good starting point and reference for the subject. Wilmott [1998] also provides some insights on the topic.
} 


\section{R eferences}

Blinder, A.; Maccini, L. J. "Taking Stock: A Critical Assessment of Recent Research on Inventories," J ournal of E conomic Perspectives, 5, Winter 1991.

Brennan, M. J. "The Supply of Storage," A merican E conomic Review, 47, 1958.

-.; Williams, D. J.; and Wright, B. "Convenience Yield without the Convenience: A Spatial Temporal Interpretation of Storage Under Backwardation," The E conomic J ournal, 107, July 1997.

Chambers, M. J.; Bailey, R. E. "A Theory of Commodity Price Fluctuations," J ournal of Political E conomy, 104, 5, 1996.

Considine, T. J. "Inventory Under Joint Production: An Empirical Analysis of Petroleum Refining," Review of Economics and Statistics, 79, 3, 1997.

Considine, T. J.; Larson, D. F. "Risk Premiums on Inventory Assets: The Case of Crude Oil and Natural Gas," J ournal of Futures Markets, 21, 3, 2001.

Dale, Charles; Zyren, John. "Petroleum Futures Markets: Volatile Prices, Controversial Functions, Stagnant Volumes," Chapter 6, in Petroleum 1996: Issues and Trends, DOE/EIA-0615, Washington, D. C., September 1997.

Deaton, A.; Laroque, Guy. "On the Behavior of Commodity Prices," Review of Economic Studies, $59,1992$.

—. "Competitive Storage and Commodity Price Dynamics," J ournal of P olitical E conomy, 104, 5, 1996.

Eichenbaum, M. S. "Some Empirical Evidence on the Production Level and Production Cost Smoothing Models of Inventory Investment," A merican E conomic Review, 79, 4, September 1989.

Enders, Walter. A pplied E conometric Time Series, John Wiley \& Sons, Inc., 1995.

Gustafson, R. L. "Carryover Levels for Grains: A Method for Determining Amounts that are Optimal under Specified Conditions," USDA Technical Bulletin 1178, 1958.

Horsnell, Paul; Mabro, Robert. Oil Markets and Prices-T he B rent Market and the Formation of W orld Oil Prices, Oxford University Press, 1993.

Hull, John C. Options, Futures, and Other Derivatives, Fourth edition, Prentice Hall Inc., 2000.

Kaldor, N. "Speculation and Economic Stability," Review of Economic Studies, 7, 1939.

Mabro, Robert. "OPEC and the Price of Oil," Energy J ournal, 13, 2, 1992.

Maccini, M. J.; Rossana, R. "Joint Production, Quasi-Fixed Factors of Production, and Investment in Finished Goods Inventory," J ournal of M oney, Credit, and Banking, 16, 1984.

Miranda, M. J.; Glauber, J. W. "Estimation of Dynamic Nonlinear Rational Expectations Models of Primary Commodity Markets with Private and Government Stockholding," Review of Economics and Statistics, 75, 1993.

Pindyck, R. S. "Inventories and the Short-Run Dynamics of Commodity Prices," Rand J ournal of E conomics, 25, 1, Spring 1994.

-. "The Dynamics of Commodity Spot and Futures Markets: A Primer," The Energy J ournal, 22, $3,2001$.

Ramey, V. A. "Inventories as Factors of Production and Economic Fluctuations," A merican E conomic Review, 79, 3, June 1989.

Razavi, Hossein; Fesharaki, Fereidun. Fundamentals of P etroleum Trading, Praeger, 1991.

Telser, L. G. "Futures Trading and the Storage of Cotton and Wheat," J ournal of Political E conomy, $66,1958$.

Thurman, W. N. "Speculative Carryover: An Empirical Examination of the U.S. Refined Copper Market," RAND J ournal of Economics, Autumn 1988.

Williams, J. C.; Wright, B. D. Storage and Commodity Markets, Cambridge: Cambridge University Press, 1991.

Wilmott, Paul. Derivatives: The Theory and Practice of F inancial Engineering, John Wiley \& Sons, 1998.

Working, H. "Theory of Inverse Carrying Charge in Futures Markets," J ournal of Farming Economics, 30, 1934. 